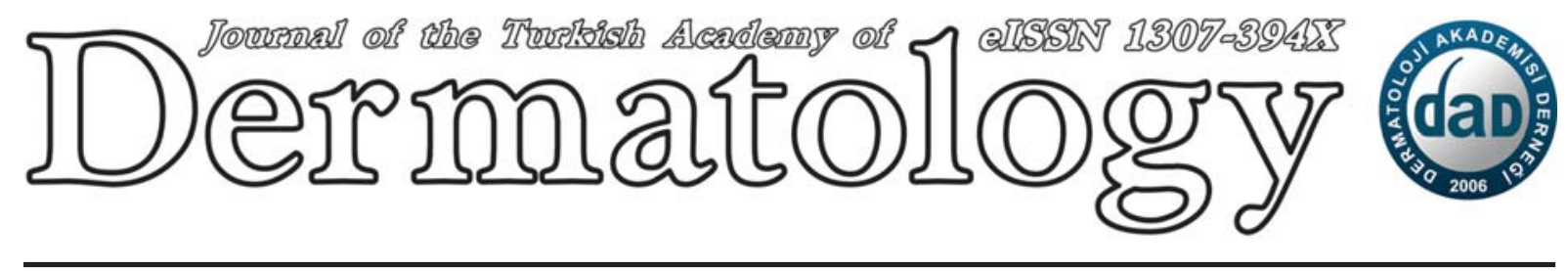

Case Report

DOI: 10.6003/jtad.1261c3

\title{
Bullous Mastocytosis in an Infant
}

\author{
Filiz Canpolat, ${ }^{1}$ MD, Hatice Akpınar, ${ }^{1}$ MD, Fatma Eskioğlu, ${ }^{1}$ MD, Demet Yılmaz, ${ }^{2}$ MD
}

\begin{abstract}
Address: Departments of ${ }^{1}$ Dermatology and ${ }^{2} 2^{\text {nd }}$ Pathology, Ministry of Health, Dişkap1 Y1ldırım Beyazıt Education and Training Hospital, Ankara, Turkey

E-mail: filizcanpolat@hotmail.com

*Corresponding Author: Dr. Filiz Canpolat. Dikmen Caddesi Salkım Söğüt Sokak No:18/9 Dikmen, 06540, Ankara, Turkey
\end{abstract}

Published:

J Turk Acad Dermatol 2012; 6 (1): 1261c3

This article is available from: http://www.jtad.org/2012/6/jtad1261c3.pdf

Key Words: Bullous, mastocytosis, infant

\begin{abstract}
Observation: We report on a 9-month-old male infant with multiple tense bullae, erosions and hemorrhagic crusts on the scalp, face and distal lower limb. He had generalised yellowish thick and rough skin, giving doughy feel and 'peau d' orange' appearance of the skin at places. The histopathological examination revealed a dense dermal cellular infiltrate identified as mast cells by toluidine blue stain. The direct immunofluorescence was negative. A diagnosis of diffuse cutaneous mastocytosis (DCM) with generalized bullae was made based on these clinical and histopathological findings. In cases with DCM with generalized bullae, systemic involvement is more frequent and more severe compared to other types of cutaneous mastocytosis. Some lethal outcomes have been reported. Therefore, proper follow-up with evaluations for systemic involvement is required for these patients.
\end{abstract}

\section{Introduction}

Mastocytosis is a rare, usually sporadic, heterogeneous group of haematopoietic disorders, characterized by an abnormal increase and accumulation of mast cells in one or more organ systems [1]. Mastocytosis may present in children as a localized mastocytoma, urticaria pigmentosa, or diffuse cutaneous mastocytosis (DCM) [2]. Bullous mastocytosis (BM), a very rare variant of $\mathrm{DCM}$, is characterised by intensely itchy, generalised yellowish, thickened skin with doughy / leathery feel and appearance of large blisters spontaneously or following mild trauma due to diffuse mast cell infiltration. Generally, it has good prognosis with tendency to spontaneous resolution $[3,4]$. We present our case with $\mathrm{BM}$ in an infant, rare entity.

\section{Case Report}

A 9-month-old boy infant presented with pruritic blisters that began 10 days ago. The lesions were first observed on the scalp and spread to the limbs especially at sites of minor trauma. He was the only child of nonconsanguineous parents and his birth and developmental history were normal. There was no history of drug ingestion before the onset of the disease. On cutaneous examination, multiple tense vesicles, bullae, erosions and hemorrhagic crusts on the scalp, face and distal lower limb were noted (Figure 1A, 1B, 1C). He had generalised yellowish thick and rough skin, giving doughy feel and 'peau d' orange' appearance of the skin at places (Figure 2). He also had recurrent episode of facial flushing. Darier's sign was positive. There were no other skin lesions. Palms, soles and oral mucosa were uninvolved. Systemic examination was within normal limits. The various 


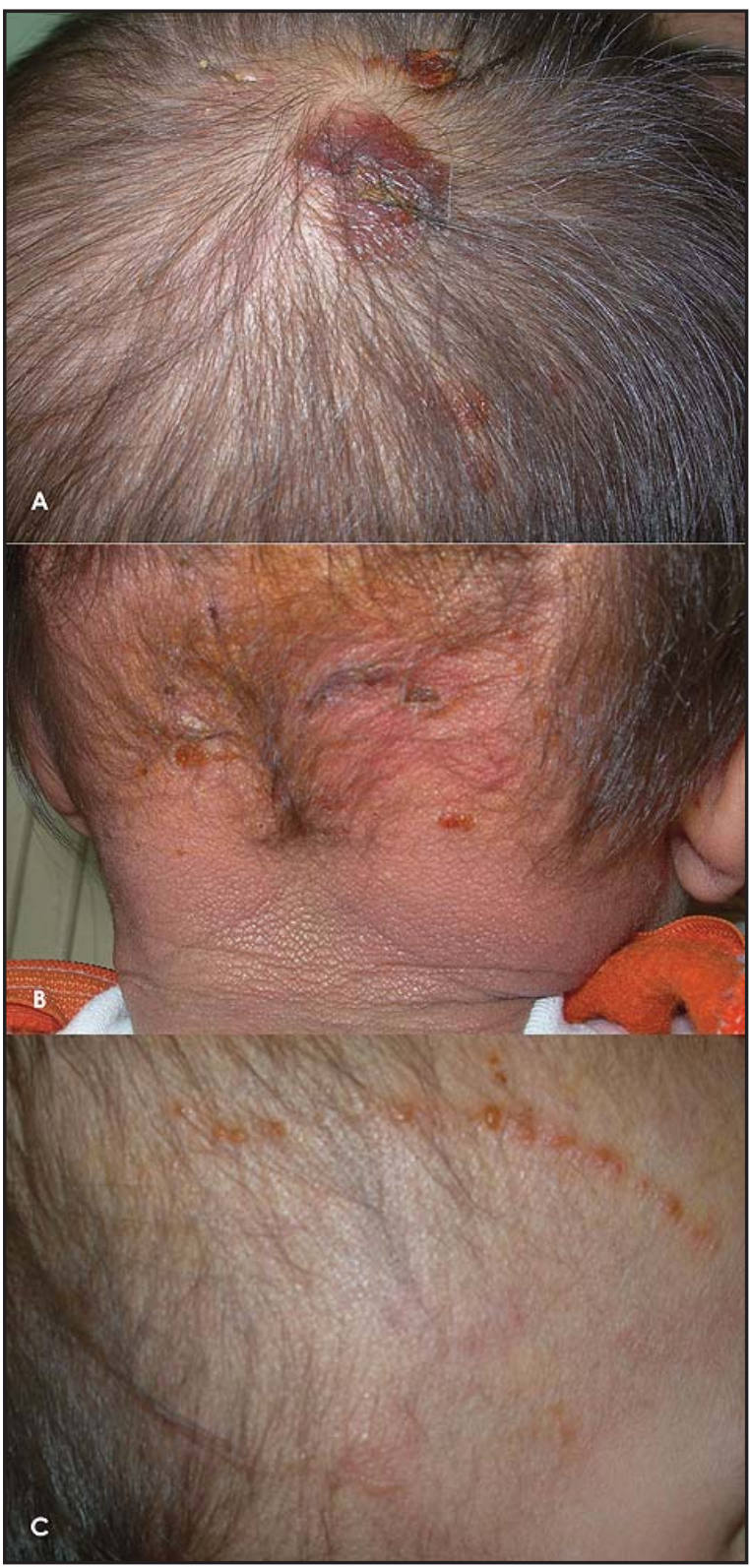

Figure 1A, 1B, 1C. Multiple tense vesicles, bullae, erosions and hemorrhagic crusts on the scalp.

laboratory investigations including complete blood count, erythrocyte sedimentation rate, urinalysis, histamine in urine, serum chemistry profile, Ig $\mathrm{E}$ and bone marrow aspiration were within the normal range or negative. No abnormal data could be seen in his abdominal and pelvic sonography. The culture from the blister was negative. Skin biopsy from a lesion showed a dense dermal cellular infiltrate identified as mast cells by toluidine blue staining (Figure 3A, 3B). The direct immunofluorescence was negative. The diagnosis of bullous mastocytosis was made based on these clinical and histopathological findings. The patient was treated with $\mathrm{H}_{1}$ and $\mathrm{H}_{2}$ blockers (hydroxizine and ranitidine) and ketotifen to which there was no sa-

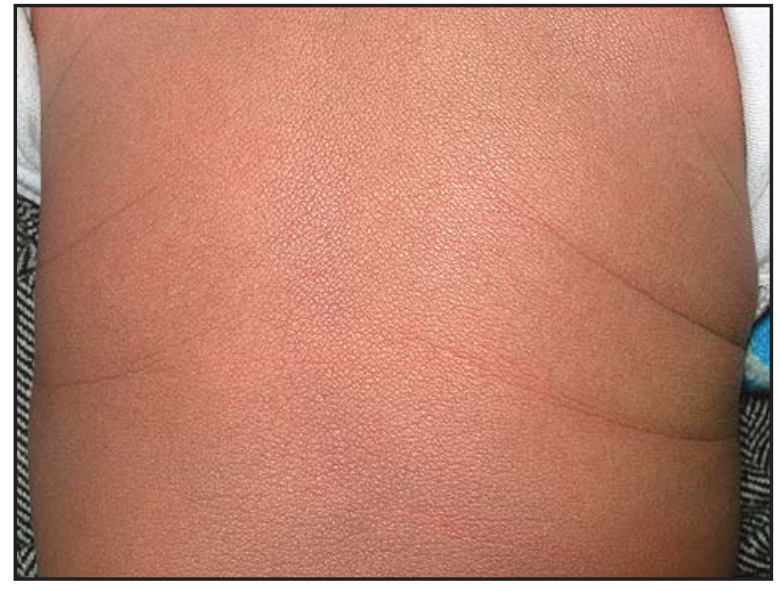

Figure 2. Peau d'orange like skin on the trunk

tisfactory response. Prednisolone in a dose of 1 $\mathrm{mg} / \mathrm{kg} /$ day given orally caused complete remission of the disease in 2 weeks. The drug was gradually tapered and stopped over the next 6 weeks. There were no side effects of the therapy. Now he gets only occasional new lesions which are managed with topical betamethasone dipropionate and oral hydroxizine.

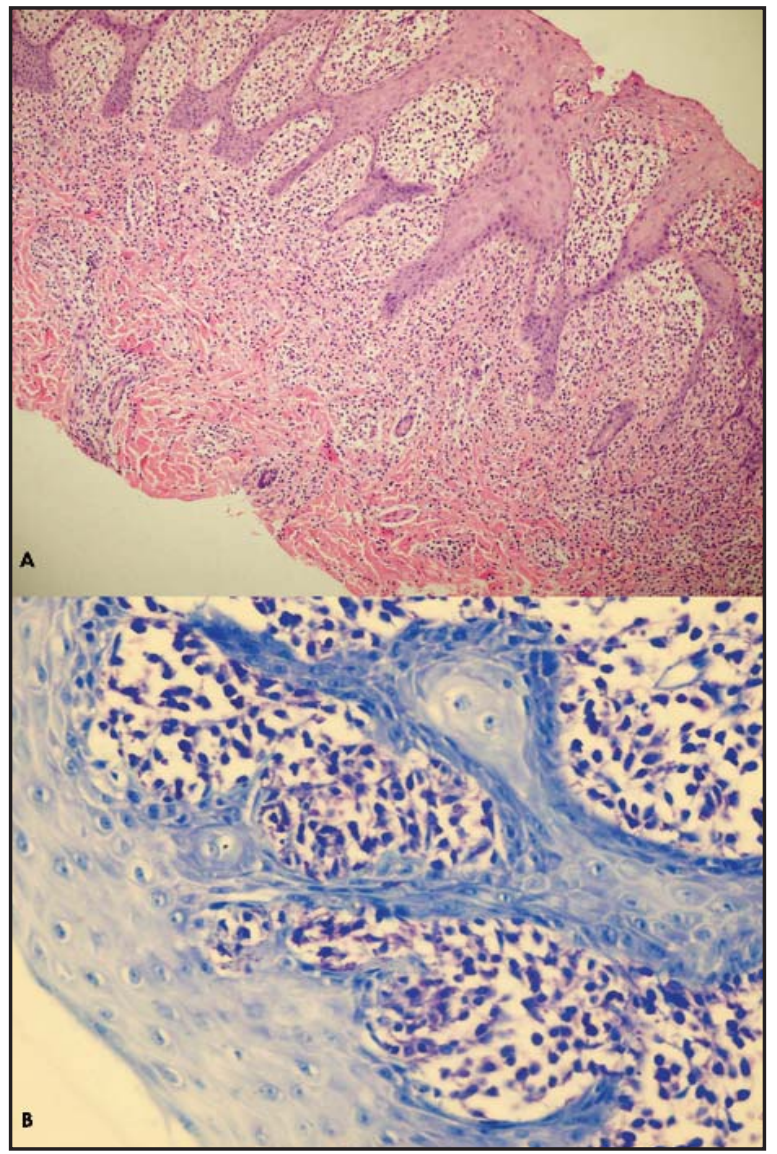

Figure 3A, 3B. Dermal mast cell infiltration was stained with hematoxylin and eosin $(\mathrm{A}: \times 200)$ and toluidin blue $(\mathrm{B}: \times 200)$.

Page 2 of 4 (page number not for citation purposes) 


\section{Discussion}

Bullous mastocytosis or diffuse cutaneous mastocytosis is a very rare and severe variant of mastocytosis which usually occurs in the first year of life [5]. There is diffuse infiltration of the skin with mast cells manifesting clinically as yellowish, thickened, fine 'cobblestoning' or 'peau $d$ ' orange' appearance of the skin as well as bullae located anywhere on the body [3]. The disease has been found to cause intense itching and variable degree of functional disturbances [6] like headache, palpitations, abdominal pain, diarrhea, dyspnea, wheezing and syncopal attacks but in some patients it has caused shock leading to a fatal outcome [7]. The etiology of the disorder is unclear however its association with the use of nonprescription cough suppressants and myeloproliferative disorders has been reported [7]. It is believed that mast cell proteases released in massive amounts can cause dermoepidermal separation leading to bullae formation [8]. A mutation in c-kit, a proto-oncogene that may contribute to an increased rate of mast cell proliferation, has been identified in adults with mastocytosis. This mutation has also been reported in children with atypical mastocytosis and, when present, may indicate a poorer prognosis [4].

Bullous mastocytosis must be considered in the differential diagnosis of an infant with a bullous eruption. If bullae are widespread, it may be mistaken for other bullous dermatoses of infancy such as bullous impetigo, epidermolysis bullosa, staphylococcal scalded skin syndrome, bullous erythema multiforme and epidermolytic hyperkeratosis [2, 9].

Treatment of bullous mastocytosis includes the use of $\mathrm{H}_{1}$ and $\mathrm{H}_{2}$ antihistamines and oral sodium cromoglycate. Sodium cromoglycate relieves the gastrointestinal and cutaneous symptoms such as pruritus and blister formation. Ketotifen, an agent similar to sodium cromoglycate but with better oral absorption, appears effective for controlling mastocytosis by inhibiting mast cell degranulation and blocking histamine receptors. Topical highpotency corticosteroids and systemic steroids may improve cutaneous mast cell lesions and symptoms of bullous mastocytosis [2]. Correia et al. reported two patients with cutaneous mastocytosis who were succesfully treated with pimecrolimus cream twice a day and oral antihistamine [10]. Anti-Ig E (Omalizumab) has also been reported to reduce attacks [11]. Imatinib mesylate has recently been reported as a treatment option for systemic mastocytosis [12]. Patients are advised to avoid drugs that may cause mast cell degranulation such as codeine, opiates, aspirin, dextromethorphan, procaine hydrochloride, polymyxin $\mathrm{B}$, alcohol, radiographic dyes, and many anesthetic agents $[\mathbf{6 , 1 1}]$.

Bullous mastocytosis is a rare form of DCM, which may mimic other bullous diseases of childhood. DCM usually resolves spontaneously but it have a higher risk for systemic involvement. Therefore, DCM with bullous eruption, as seen in our patient, proper follow-up with evaluations for systemic involvement is required.

\section{References}

1. Akoglu G, Erkin G, Cakir B, Boztepe G, Sahin S, Karaduman A, Atakan N, Akan T, Kolemen F. Cutaneous mastocytosis: demographic aspects and clinical features of 55 patients. J Eur Acad Dermatol Venereol 2006; 20: 969-973. PMID: 16922947

2. Tay YK, Kwok YK, Lee YS. Generalized bullous eruption in an infant. Pediatr Dermatol 2005; 22: 79-81. PMID: 15660905

3. Verma KK, Bhat R, Singh MK. Bullous mastocytosis treated with oral betamethasone therapy. Indian $\mathrm{J}$ Pediatr 2004; 71: 261-263. PMID: 15080414

4. Avshalumov K, Pichardo R, Jorizzo JL, Sangueza OP, Goldenberg G. Bullous mastocytosis: report of a patient and a brief review of the literature. Am J Dermatopathol 2008; 30: 455-457. PMID: 18806488

5. Hartmann K, Henz BM. Mastocytosis: recent advances in defining the disease. Br J Dermatol 2001; 144: 682-695. PMID:11298525

6. Warin RP, Hughes RC. Diffuse cutaneous mastocytosis. Br J Dermatol 1963; 65: 296-297. PMID: 14046151

7. Cook J, Stith M, Sahn EE. Bullous mastocytosis in an infant associated with the use of a nonprescription cough suppressant. Pediatr Dermatol 1996; 13: 410-414. PMID: 8893244

8. Longley J, Duffy TP, Kohn S. The mast cell and mast cell disease. J Am Acad Dermatol 1995; 32: 545-561. PMID: 7896943 
9. Lee EH, Kim MR, Kang TW, Kim SC. Diffuse cutaneous mastocytosis with generalized bullae. Ann Dermatol 2010; 22: 77-80. PMID: 20548889

10. Correia O, Duarte AF, Quirino P, Azevedo R, Delgado L. Cutaneous mastocytosis: Two pediatric cases treated with topical pimecrolimus. Dermatol Online J 2010; 15; 16: 8. PMID: 20492825
11. Heide R, Beishuizen A, De Groot H, Den Hollander JC, Van Doormaal JJ, De Monchy JG. Mastocytosis in children: a protocol for management. Pediatr Dermatol 2008; 25: 493-500. PMID: 18789103

12. Pottier P, Planchon B, Grossi O. Complete remission with imatinib mesylate (Glivec) of an idiopathic hypereosinophilic syndrome associated with a cutaneous mastocytosis after failure of interferon-alpha. Rev Med Interne 2003; 24: 542-546. PMID: 12888176 